\title{
Spectrum Occupancy Measurement of Cellular Spectrum and Smart Network Sharing in Pakistan
}

\author{
Aftab Ahmed Mirani ${ }^{1}$, Sajjad Ali Memon², Saqib Hussain ${ }^{3}$, Muhammad Aamir Panhwar ${ }^{4}$, Syed Rizwan Ali Shah ${ }^{5}$ \\ Department of Telecommunication Engineering, Mehran University of Engineering and Technology, Jamshoro, Pakistan 1, 2, 3,5 \\ School of Electronic Engineering, Beijing University of Posts and Telecommunications, China ${ }^{4}$
}

\begin{abstract}
In wireless communication, the radio spectrum is a very rare and precious resource that has currently become a major problem to efficiently exploit the underutilized band of the static allocated licensed band. Recently, the cognitive radio (CR) has emerged as a promising technology to overcome the spectrum crisis, in which, the licensed band can be utilized by the unlicensed user until and unless it does not affect the transmission of the licensed band. In this paper, the spectrum occupancy of three bands i.e. GSM 900, 1800 and 2100 bands have been measured through spectrum analyzer in the indoor and outdoor environment. The measured results of all the three bands have been calculated through MATLAB against the power spectral density versus frequency plots. Results have shown that the majority of the licensed band is underutilized. Therefore, the CR can play a pivotal role to efficiently utilize the unused spectrum and to overcome the cellular wireless spectrum crisis in Pakistan. The second part of this paper deals with the emerging concept of network sharing among mobile operators and its impacts on cost. Network sharing become the standard among mobile operators worldwide and so in Pakistan. Capital (CAPEX) as well as operational (OPEX) expenditure and rapid advancement in technology encouraged all operators to go for sharing business models. In Pakistan, all four mobile operators Jazz, Telenor, Zong, and Ufone are actively adopting this model to maintain EBITDA (earnings before interest, taxes, depreciation, and amortization). Mainly there are two types of network sharing, Passive infrastructure sharing, and active resource sharing. Passive network sharing is widely used in Pakistan among operators.
\end{abstract}

Keywords-Cognitive radio; spectrum occupancy; cellular networks; spectrum analyzer; mobile network operators; sharing models; passive infrastructure sharing

\section{INTRODUCTION}

With the rapid evolution in wireless technological services, the demand to provide ubiquitous high data rates are increasing exponentially. This leads to utilizing the spectrum resource efficiently [1]-[2]. Thus, researchers have come up with an idea to utilize the unused spectrum through smart sensing of available spectrum through various technologies such as cognitive radio (CR). The CR can effectively deal with the spectrum scarcity problems also; it permits secondary users (SUs) to use the unoccupied spectrum without affecting the transmission of primary users (PUs)[3]-[4]. In the meantime, the Federal Communication Commission (FCC) investigated the spectrum occupancy and found that a major portion of the available spectrum is unused due to the static allocation technique [5][6][7]. The CR technology is viewed as an efficient solution to mitigate the spectrum scarcity problem, which is expected to be used in $5 \mathrm{G}$ technologies. A $\mathrm{CR}$ is a smart communication system that senses the unused spectrum in its surrounding environment and adjusts its spectrum utilization according to its environment [8].

Dynamic Spectrum Access (DSA) is considered one of the predominant approaches to address the challenges of the unutilized spectrum. In DSA, the spectrum sensing is the first step to utilize the spectrum [9]. The primary user is preferred to use the band or channel over a secondary user whereby, a secondary user utilizes the available band in the absence of a primary user [10]. Different frequency bands have been considered in order to be utilized with a DSA. Out of which Very High Frequency (VHF) and Ultra High Frequency (UHF) bands are the most favorable ones. These bands are traditionally used for different applications such as for TV broadcasting, as an outcome, empty channels or frequency in these traditional bands are often called TV White Spaces (TVWSs) [11]. Several international regulatory bodies have proposed solutions to utilize spectral opportunities in TVWSs. One of the most important IEEE standards is IEEE 802.22 which was approved by IEEE in 2011 [12].

The number of subscribers of cellular networks worldwide is increasing at a very fast pace; with almost 164 million subscribers in Pakistan alone. There is an incessant requirement to build Cellular Network infrastructure to meet the demands of the ever-increasing number of mobile users and provide better services, mainly consists of a voice call, short message services (SMS) and data services. The main infrastructure is the Global System of Mobile Telecommunications (GSM) Base station that consists of the Base Transceiver System (BTS). In order to enhance footprint across the country at a rapid pace became challenging for every operator due to high Capital expenditure (CAPEX), increasing operational expenses (OPEX), government regulatory bodies' approvals, taxations, security issues, and infrastructure expenses, etc. To mitigate these challenges, the concept of network sharing emerged and opened new doors of opportunities for Mobile network operators [13]. Currently, there are four mobile operators Jazz, Telenor, Zong, and Ufone; serving the Pakistan Telecom industry and facing the same challenges [14]. This paper provides different scenarios of Network sharing among Mobile operators in Pakistan and the impact of Infrastructure sharing.

In the same context, whenever any operator intends for rollout, it involves huge investment and the necessity to recover it by imposing big charges on subscribers. This leads to less affordability and eventually discourages mobile service 
providers to shift towards the next generations in this competitive market [15]. More or less, this problem is addressed with the help of network sharing business model in Pakistan. There are several pros of cellular sharing, increased revenue generation, growth in the number of subscribers and market penetration, fast network roll-out, avoids environmental hazardous, maintained control over mobility and above all the significant reduction in cost [16]. However, there are a few cons also, operators may lose independence over network strategy, the hidden cost may affect the revenue of a particular cluster and it is impossible to foresee everything that has to be the part of this agreement. Apparently, the advantages overweigh the disadvantages and it appeals to every mobile operator in the country to adopt the sharing business models for their future strategy.

In this paper, the spectrum occupancy measurement of all the GSM cellular operators of Pakistan in measured through spectrum analyzer in three different bands i.e. 900, 1800 and 2100 bands. The measurements are calculated at different locations of Pakistan including the Telecommunication Department of Mehran University of Engineering \& Technology, Jamshoro on several days during university lab hours. The results are carried out in the form of power spectral density (PSD) for different bands of cellular operators working in Pakistan and its bandwidth utilization percentage. The measured results are very helpful for regulatory authorities such as Pakistan Telecommunication Authority (PTA) to revise spectrum occupancy policies and to promote strong competition among cellular operators and cheap rates because every operator intends to have less CAPEX \& OPEX.

The formation of this paper is as follows. Section I contains the introduction. The measurement setup and occupancy measurement method are explained in Section II. The measured results are described in Section III. Section IV contains the concluding remarks and future work.

\section{MEASUREMENT SETUP AND METHOD}

\section{A. Measurement Setup}

The spectrum occupancy measurements have been carried out at various locations of the Sindh region such as Nooriabad, Hyderabad, Autobahn Road, Qasimabad, Site Area and TD of MUET Jamshoro using Rohde \& Schwarz FSH6 handheld spectrum analyzer (SA). The SA can operate in the range of $100 \mathrm{KHz}$ to $6 \mathrm{GHz}$. The spectrum occupancy measurement setup has been demonstrated in Fig. 1, which shows that the GSM 900 antenna is attached to SA via optical fiber cable and the SA is connected to a laptop via optical USB cable. Moreover, the antenna configuration is shown in Table I. The measurements have been carried out for a month at different places of Sindh Region, Pakistan and each measurement has been carried out for about 30 minutes. The Rhode \& Schwarz FSH view and MATLAB have been utilized to take records and plot them, respectively.

\section{B. Cellular Operators of Pakistan}

There are four GSM cellular mobile service providers working in Pakistan i.e. Telenor, Pakistan Mobile Communication Limited (PMCL/JAZZ), Ufone and Zong. These four cellular operators are using different techniques such as GSM, WCDMA, LTE and LTE-A services to provide its customers ubiquitous high-quality voice and data services[17]. The general methodology is illustrated in the flowchart given below in Fig. 2. The SA settings for GSM service providers and GSM 900, DCS 1800 and 2100 bands in Pakistan are illustrated in Table II.

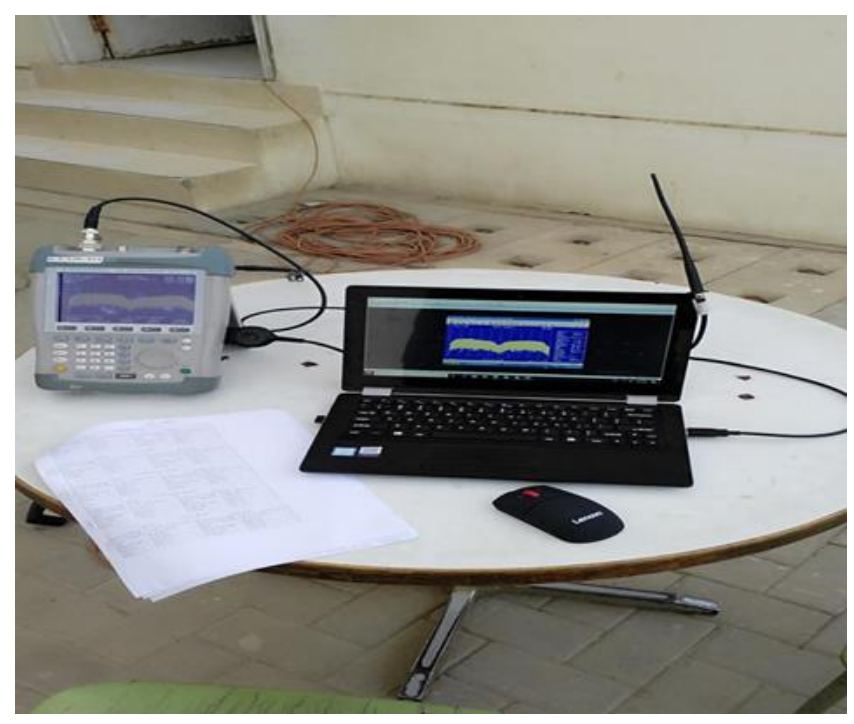

Fig 1. Spectrum Occupancy Measurement Setup.

TABLE I. ANTENNA CONFIGURATION

\begin{tabular}{|c|c|}
\hline \multicolumn{2}{|l|}{ Electrical Configuration } \\
\hline Antenna model & AMXT-900-3 \\
\hline Frequency (MHz) & $824-960$ \\
\hline Bandwidth (MHz) & 136 \\
\hline Gain (dBi) & 3 \\
\hline VSWR & $\leq 2$ \\
\hline Impedance & $50 \Omega$ \\
\hline Polarization & Vertical \\
\hline Maximum input power (W) & 50 \\
\hline Input connector type & SMA male \\
\hline \multicolumn{2}{|l|}{ Mechanical Configuration } \\
\hline Radome Color & Black \\
\hline Antenna height (mm) & 210 \\
\hline Antenna weight (g) & 20 \\
\hline Operating temperature $\left({ }^{\circ} \mathrm{c}\right)$ & -40 to 60 \\
\hline
\end{tabular}


TABLE II. The SA SETtings FOR GSM SERVICE Providers GSM 900 BAND IN PAKISTAN

\begin{tabular}{|c|c|c|c|c|c|c|c|c|}
\hline \multicolumn{2}{|c|}{ SA parameters } & \multirow{2}{*}{$\begin{array}{l}\text { Frequency range } \\
(\mathrm{MHz})\end{array}$} & \multirow{2}{*}{$\begin{array}{l}\text { Center } \\
\text { frequency } \\
(\mathrm{MHz})\end{array}$} & \multirow{2}{*}{$\begin{array}{l}\text { Frequency } \\
\operatorname{span}(\mathrm{MHz})\end{array}$} & \multirow{2}{*}{$\begin{array}{l}\text { Resolution } \\
\text { Bandwidth } \\
(\mathrm{KHz})\end{array}$} & \multirow{2}{*}{$\begin{array}{l}\text { Video } \\
\text { Bandwidth } \\
(\text { KHz })\end{array}$} & \multirow{2}{*}{$\begin{array}{l}\text { Sweep } \\
\text { time (ms) }\end{array}$} & \multirow{2}{*}{$\begin{array}{l}\text { Number of frequency } \\
\text { measurement points }\end{array}$} \\
\hline GSM Servic & roviders & & & & & & & \\
\hline \multirow{2}{*}{ Mobilink } & Uplink & $907.3-914.9$ & 911.1 & 7.6 & 200 & 200 & 250 & 301 \\
\hline & Downlink & $952.3-959.9$ & 956.1 & 7.6 & 200 & 200 & 250 & 301 \\
\hline \multirow{2}{*}{ Ufone } & Uplink & 894.9-902.5 & 898.7 & 7.6 & 200 & 200 & 250 & 301 \\
\hline & Downlink & 939.9-947.5 & 943.7 & 7.6 & 200 & 200 & 250 & 301 \\
\hline \multirow{2}{*}{ Telenor } & Uplink & $902.5-907.3$ & 904.9 & 4.8 & 200 & 200 & 250 & 301 \\
\hline & Downlink & $947.5-952.3$ & 949.9 & 4.8 & 200 & 200 & 250 & 301 \\
\hline \multirow{2}{*}{ Warid } & Uplink & $890.1-894.9$ & 892.5 & 4.8 & 200 & 200 & 250 & 301 \\
\hline & Downlink & $935.1-939.9$ & 937.5 & 4.8 & 200 & 200 & 250 & 301 \\
\hline \multirow{2}{*}{ Zong } & Uplink & $882.5-890.1$ & 886.3 & 7.6 & 200 & 200 & 250 & 301 \\
\hline & Downlink & $927.5-935.1$ & 931.3 & 7.6 & 200 & 200 & 250 & 301 \\
\hline \multirow{2}{*}{ GSM 900} & Uplink & $890-915$ & 902.5 & 25 & 200 & 200 & 250 & 301 \\
\hline & Downlink & $935-960$ & 947.5 & 25 & 200 & 200 & 250 & 301 \\
\hline \multirow{2}{*}{ DCS 1800} & Uplink & 1718.9-1781.1 & 1750 & 62.2 & 200 & 200 & 250 & 301 \\
\hline & Downlink & 1813.9-1876.1 & 1845 & 62.2 & 200 & 200 & 250 & 301 \\
\hline \multirow{2}{*}{2100} & Uplink & $1920-1950$ & 1935 & 30 & 200 & 200 & 250 & 301 \\
\hline & Downlink & $2110-2140$ & 2125 & 30 & 200 & 200 & 250 & 301 \\
\hline
\end{tabular}

\section{OCCUPANCY RESULTS AND DISCUSSIONS}

Start

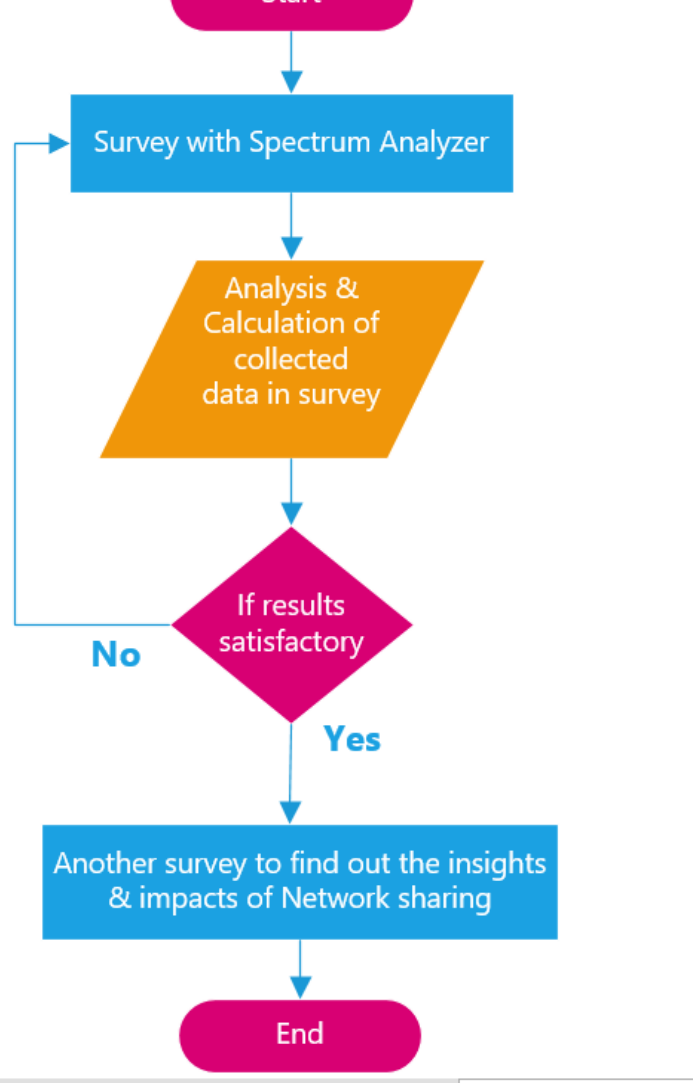

Fig 2. Flowchart of Research Methodology.
The results of the SA measurement are represented in the average power spectral density (APSD) versus frequency plots in the MATLAB. The APSD is measured by averaging all the values gathered during a 30 days' measurement campaign for different bands i.e. GSM 900, 1800 and 2100 bands. The occupied spectrum calculation is done by setting a threshold level (a solid black line marked as a threshold level in all figures) as shown in Fig. 3 to Fig. 30. The half-power threshold is indicated by adding $3 \mathrm{dBm}$ in the minimum received power signal. If the measured APSD of a specific frequency is beyond the threshold level, then the certain frequency is called as occupied frequen, cy. The percentage of spectrum occupancy can be calculated as described in Eq. 1.

$\mathrm{SO}=\frac{P_{T}}{P} \times 100 \%$

Where $\mathrm{P}_{\mathrm{T}}$ denotes the number of frequency measurements that exceed the selected threshold level and $\mathrm{P}$ is the total number of frequency measurement points in the specific spectrum band.

\section{A. Mobilink}

Mobilink started its cellular services as a pioneer operator in Pakistan in 1994 [18]. Recently, they have won the $10 \mathrm{MHz}$ spectrum in the $1800 \mathrm{MHz}$ band. Mobilink and Warid merged into a single company on November 26, 2015. Also, the recent merger of Jazz and Warid increased their subscribers of about 49 million around the country.

The results of indoor and outdoor GSM 900 uplink and downlink spectrum occupancies are represented in Fig. 3, 4, 5 and 6 , respectively. The measured results of indoor spectrum 
occupancy for both uplink and downlink spectrum bands are $61.794 \%$ and $61.4618 \%$, respectively. These results conclude that a $5.82 \mathrm{MHz}$ spectrum band is unutilized out of the total 15.2 $\mathrm{MHz}$ spectrum band. Similarly, the measured results of outdoor spectrum occupancy for both uplink and downlink spectrum bands are $58.1362 \%$ and $68.7708 \%$ respectively. These results conclude that a $5.47 \mathrm{MHz}$ spectrum band is unutilized out of the total $15.2 \mathrm{MHz}$ spectrum band.

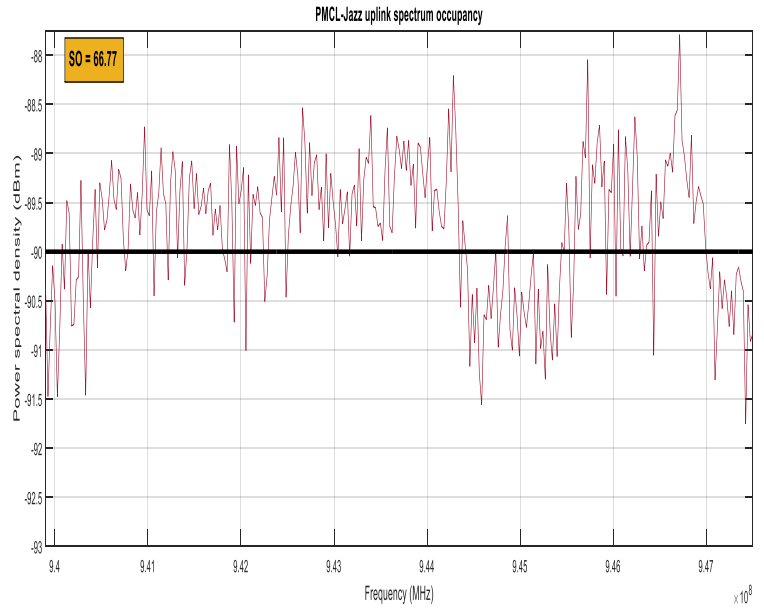

Fig 3. PMCL-Jazz uplink Spectrum Occupancy.

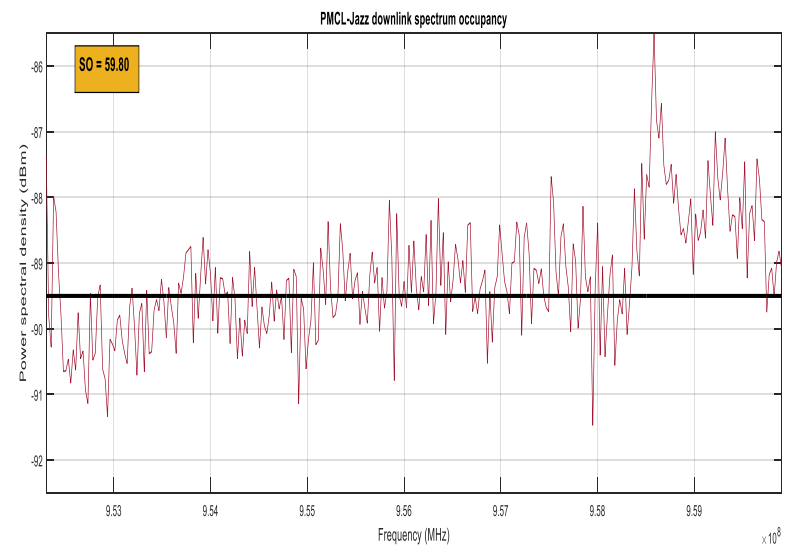

Fig 4. PMCL-Jazz Downlink Spectrum Occupancy.

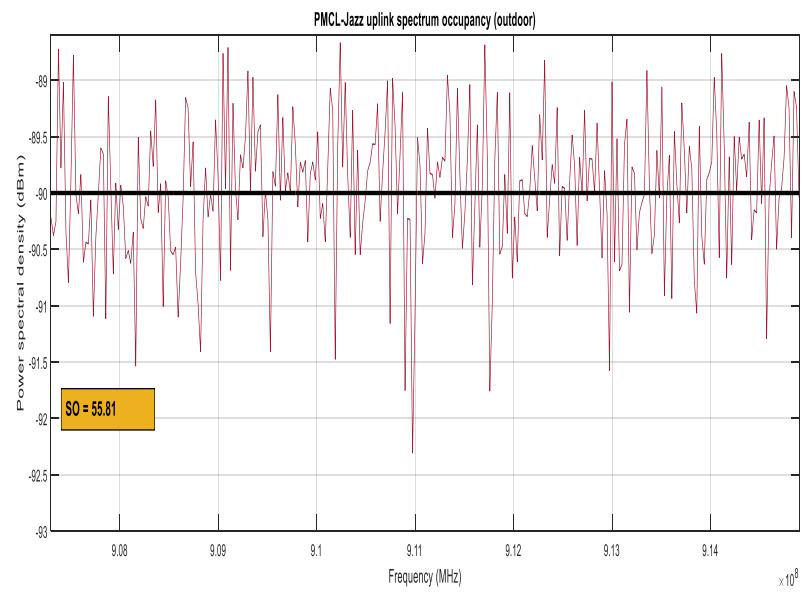

Fig 5. PMCL-Jazz uplink Spectrum Occupancy (Outdoor).

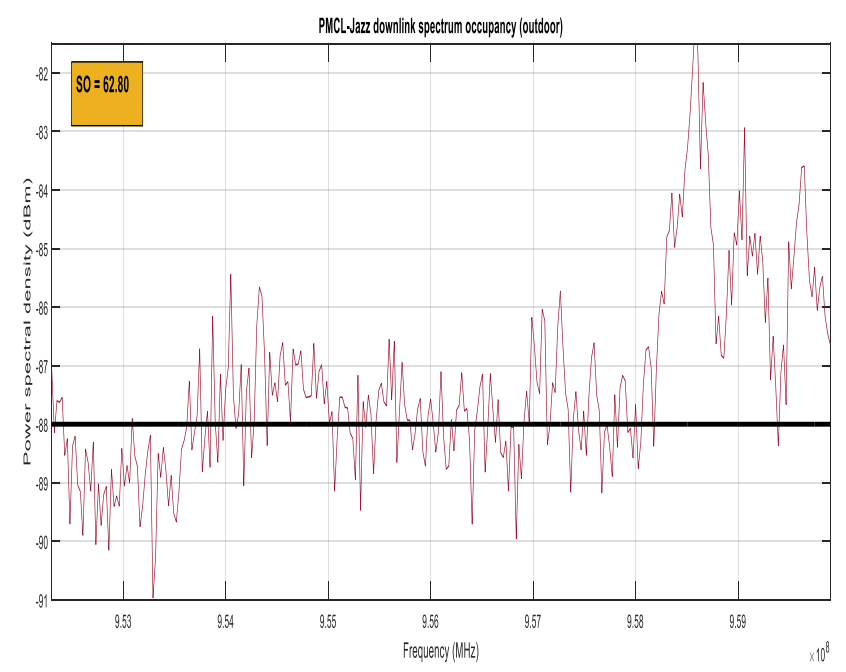

Fig 6. PMCL-Jazz Downlink Spectrum Occupancy (Outdoor).

\section{B. UFONE}

UFONE initiated its cellular services in Pakistan on January 29, 2001. Recently, it has launched its 4G services in major cities of Pakistan on February 9, 2019[19].

The measured results of indoor and outdoor GSM 900 uplink and downlink spectrum occupancies are illustrated in Fig. 7, 8, 9 and 10, respectively. The measured results of indoor spectrum occupancy for both uplink and downlink spectrum bands are $42.1927 \%$ and $91.0299 \%$ respectively. These results conclude that a $4.8 \mathrm{MHz}$ spectrum band is unutilized out of the total $15.2 \mathrm{MHz}$ spectrum band. Similarly, the measured results of outdoor spectrum occupancy for both uplink and downlink spectrum bands are $63.1229 \%$ and $86.711 \%$ respectively. These results conclude that a $3.8 \mathrm{MHz}$ spectrum band is unutilized out of the total $15.2 \mathrm{MHz}$ spectrum band.

\section{Telenor}

Telenor [17] is a multinational telecommunications company and it launched its GSM cellular services in the main cities of Pakistan on March 15, 2005. They have also won a $4 \mathrm{G}$ license spectrum of $10 \mathrm{MHz}$ block in $850 \mathrm{MHz}$ in Pakistan.

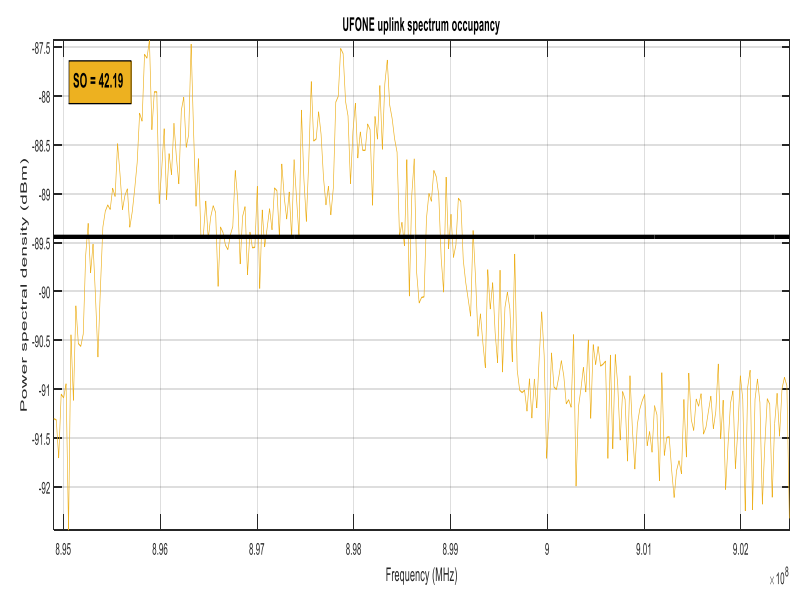

Fig 7. Ufone uplink Spectrum Occupancy. 


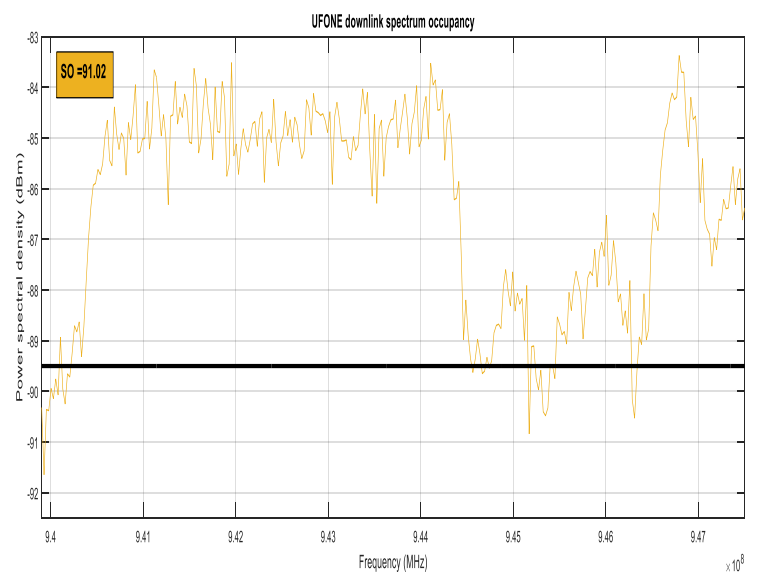

Fig 8. Ufone Downlink Spectrum Occupancy.

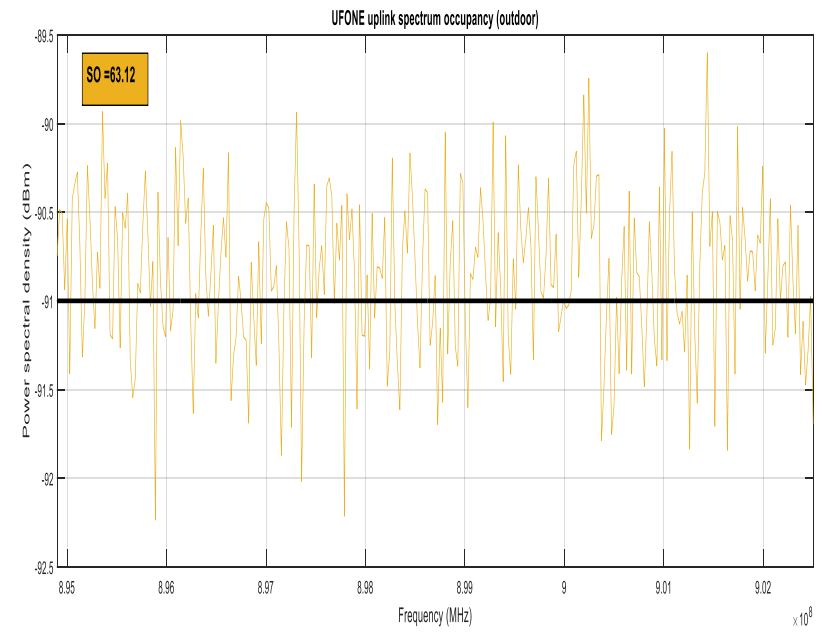

Fig 9. Ufone uplink Spectrum Occupancy (Outdoor).

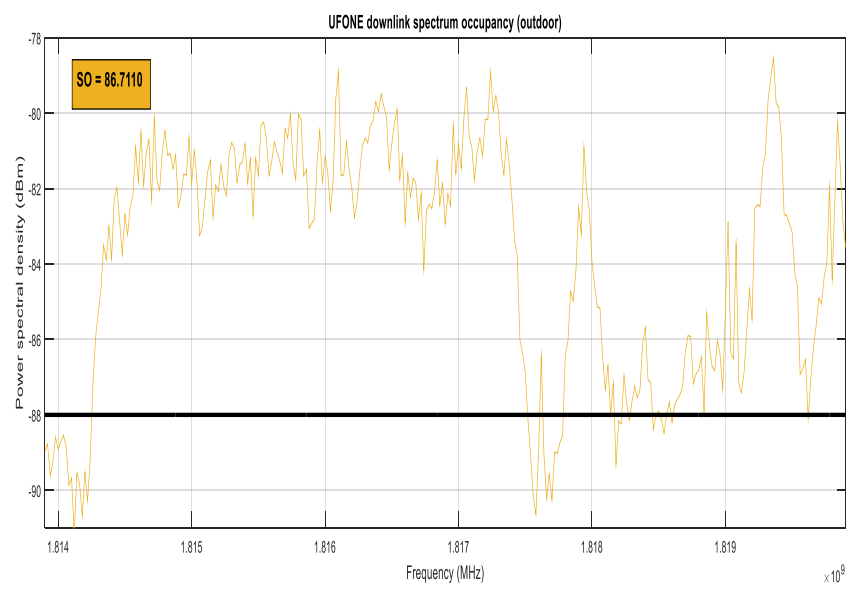

Fig 10. Ufone Downlink Spectrum Occupancy (Outdoor).

The results of indoor and outdoor GSM 900 uplink and downlink spectrum occupancies are represented in Fig. 11, 12, 13 and 14, respectively. The measured results of indoor spectrum occupancy for both uplink and downlink spectrum bands are $66.113 \%$ and $60.7973 \%$, respectively. These results conclude that a $3.51 \mathrm{MHz}$ spectrum band is unutilized out of the total $9.6 \mathrm{MHz}$ spectrum band. Similarly, the measured results of outdoor spectrum occupancy for both uplink and downlink spectrum bands are $56.4784 \%$ and $66.7774 \%$ respectively. These results conclude that a $3.67 \mathrm{MHz}$ spectrum band is unutilized out of the total $9.6 \mathrm{MHz}$ spectrum band.

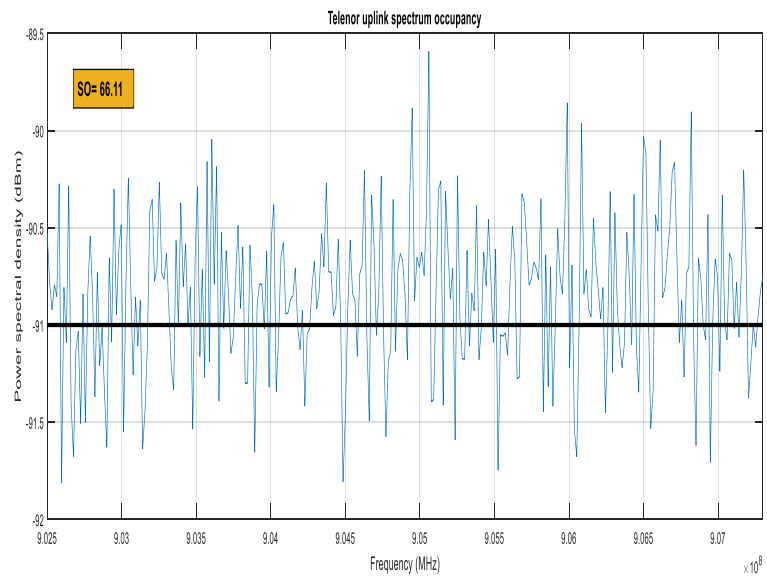

Fig 11. Telenor uplink Spectrum Occupancy.

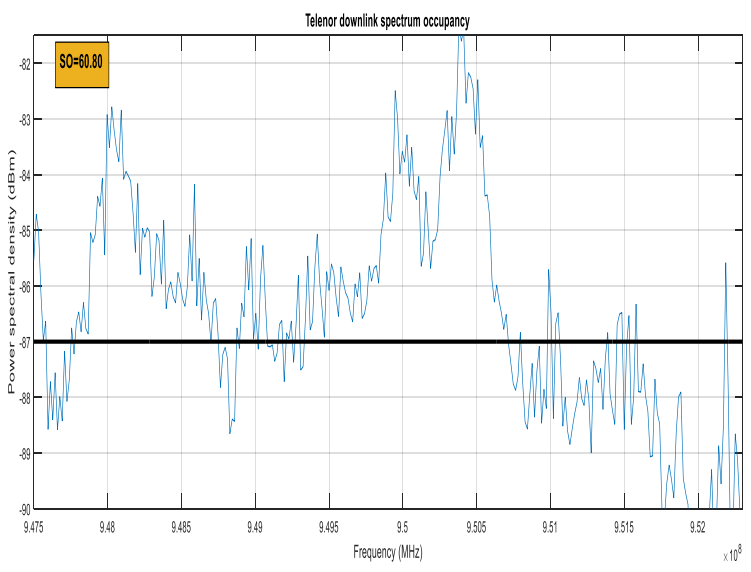

Fig 12. Telenor Downlink Spectrum Occupancy.

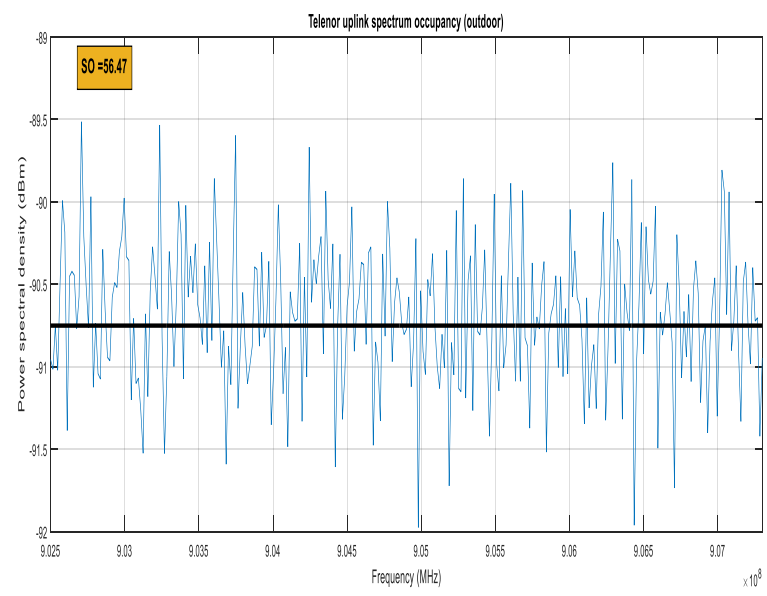

Fig 13. Telenor uplink Spectrum Occupancy (Outdoor). 


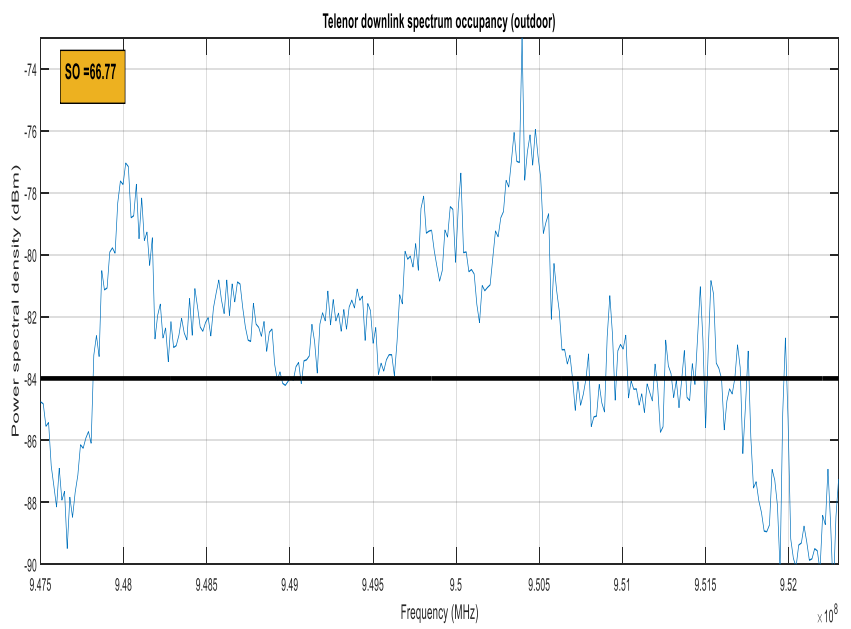

Fig 14. Telenor Downlink Spectrum Occupancy (Outdoor).

\section{ZONG}

Zong is the only cellular operator that is being owned by China and it launched its operation in Pakistan 1991 as Paktel by Cable \& Wireless. Also, it is one of the first company which is allowed a free license to provide cellular phone services. Recently PTA has allotted a six months 5G trial license to check its coverage on non-commercial-basis [20].

The results of indoor and outdoor GSM 900 uplink and downlink spectrum occupancies are represented in Fig. 15, 16, 17 and 18, respectively. The measured results of indoor spectrum occupancy for both uplink and downlink spectrum bands are $69.103 \%$ and $88.0399 \%$ respectively. These results conclude that the $3.34 \mathrm{MHz}$ spectrum band is unutilized out of the total 15.2 MHz spectrum band. Similarly, the measured results of outdoor spectrum occupancy for both uplink and downlink spectrum bands are $62.4585 \%$ and $81.3953 \%$ respectively. These results conclude that the $4.26 \mathrm{MHz}$ spectrum band is unutilized out of the total $15.6 \mathrm{MHz}$ spectrum band.

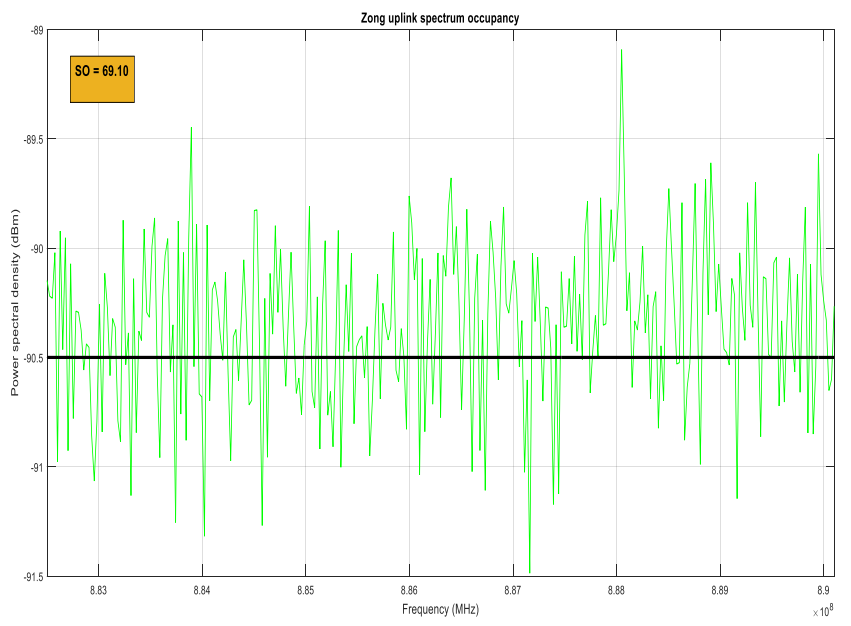

Fig 15. Zong uplink Spectrum Occupancy.

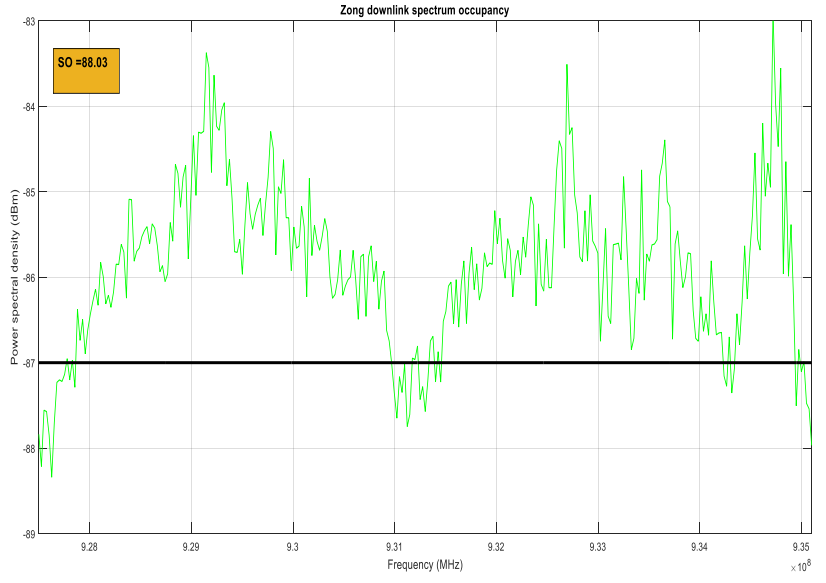

Fig 16. Zong Downlink Spectrum Occupancy.

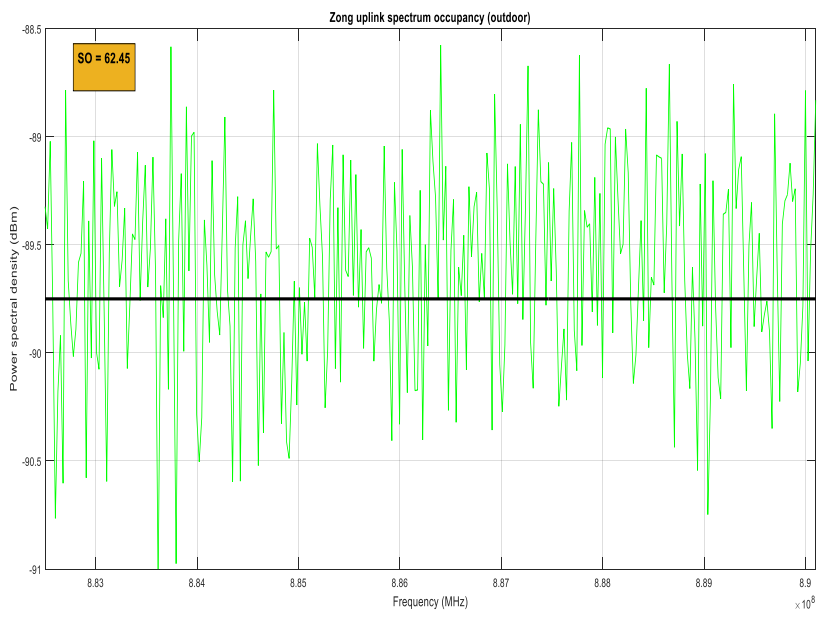

Fig 17. Zong uplink Spectrum Occupancy (Outdoor).

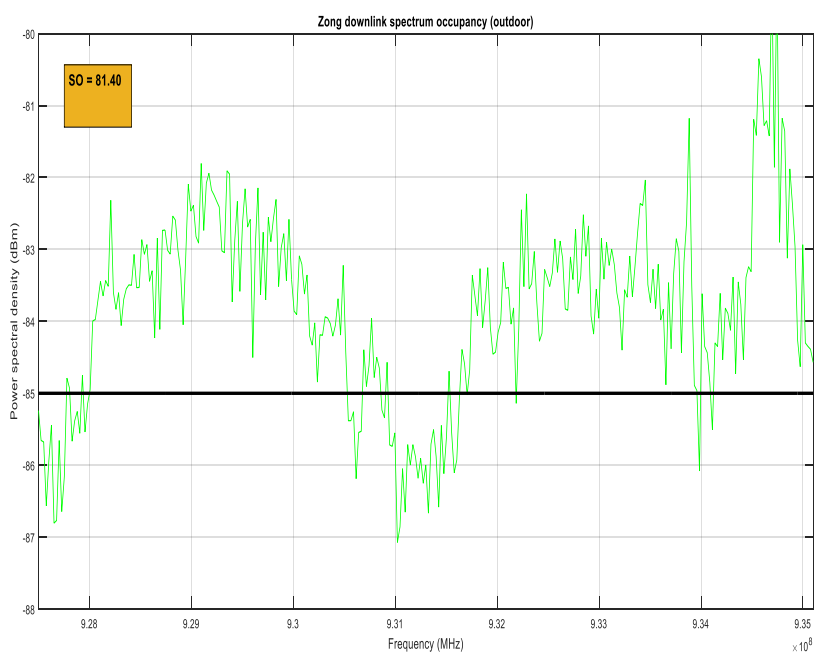

Fig 18. Zong Downlink Spectrum Occupancy (Outdoor). 


\section{E. GSM 900}

The results of indoor and outdoor GSM 900 uplink and downlink spectrum occupancies are represented in Fig. 19, 20, 21 and 22, respectively. The measured results of indoor spectrum occupancy for both uplink and downlink spectrum bands are $57.1429 \%$ and $53.8206 \%$ respectively. These results conclude that $22.25 \mathrm{MHz}$ spectrum band is unutilized out of the total $64.8 \mathrm{MHz}$ spectrum band. Similarly, the measured results of outdoor spectrum occupancy for both uplink and downlink spectrum bands are $77.7409 \%$ and $56.8106 \%$ respectively. These results conclude that $16.35 \mathrm{MHz}$ spectrum band is unutilized out of the total $64.8 \mathrm{MHz}$ spectrum band.

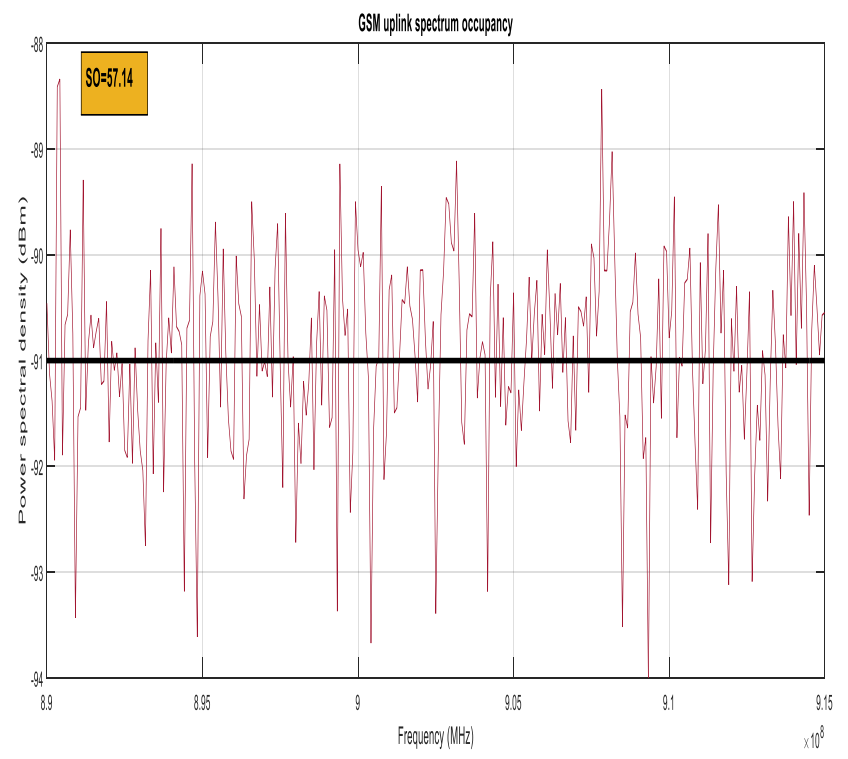

Fig 19. GSM 900 uplink Spectrum Occupancy.

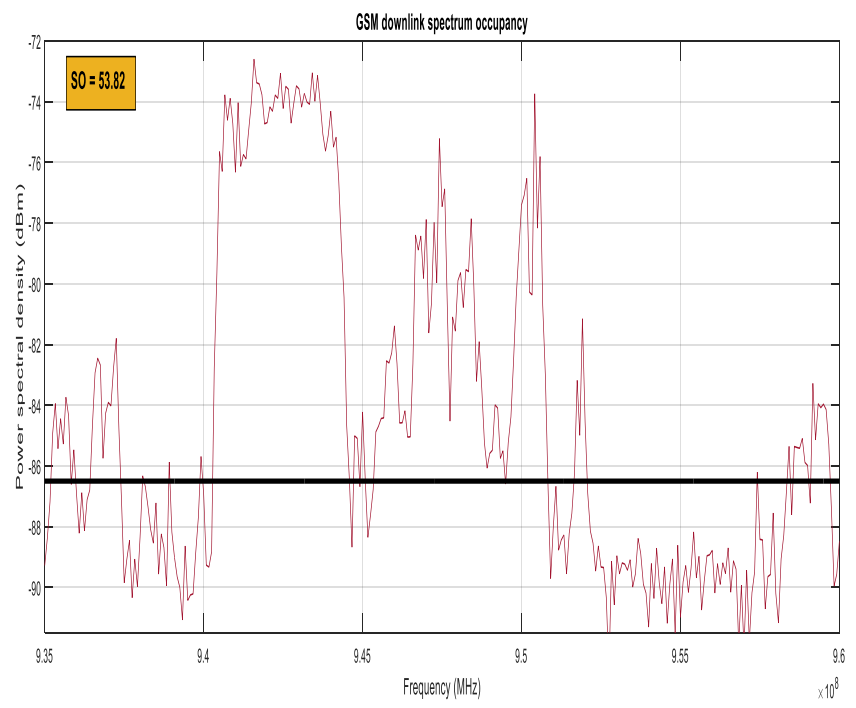

Fig 20. GSM 900 Downlink Spectrum Occupancy.

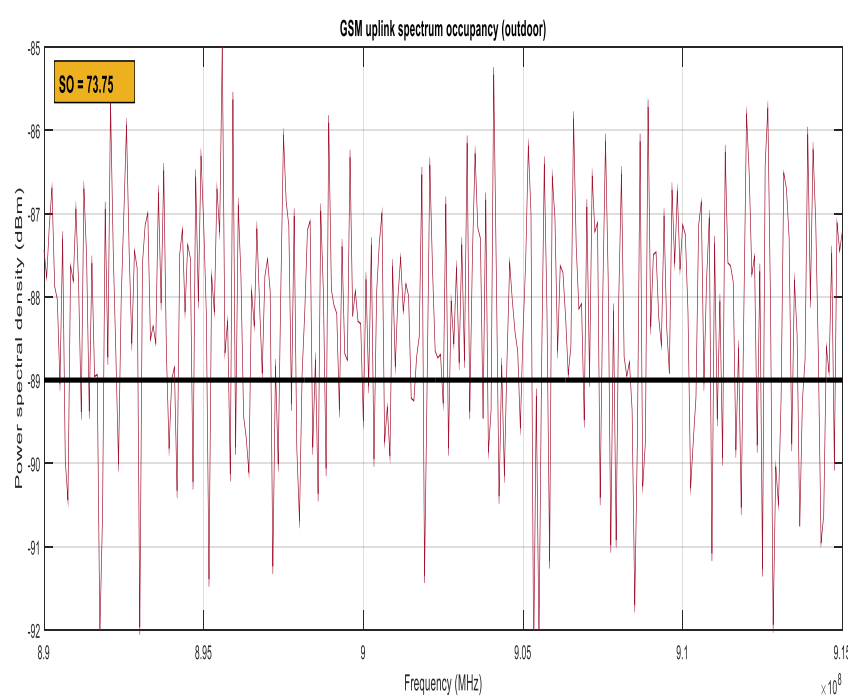

Fig 21. GSM 900 uplink Spectrum Occupancy (Outdoor).

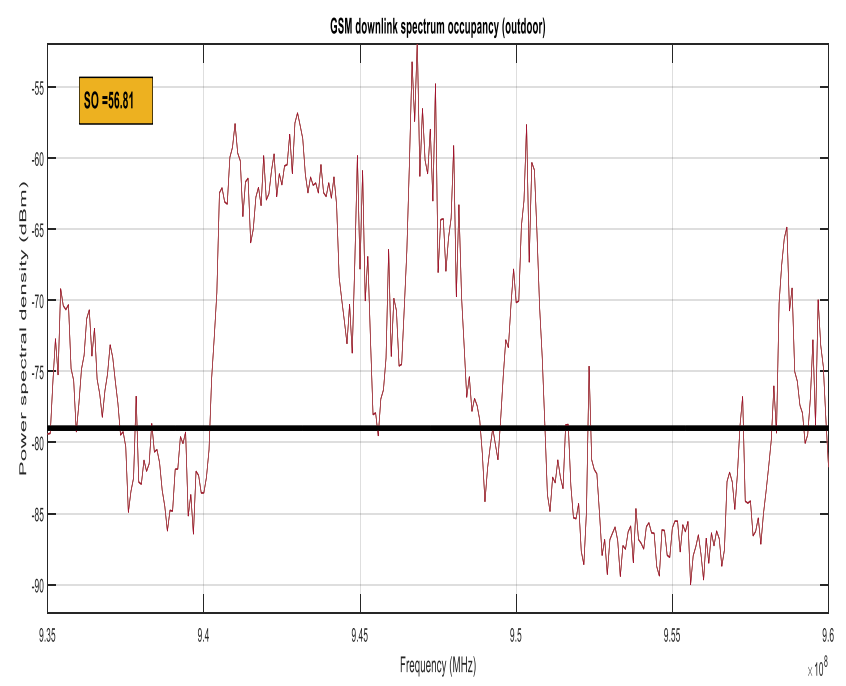

Fig 22. GSM 900 Downlink Spectrum Occupancy (Outdoor).

\section{F. DCS 1800}

The measured results of indoor and outdoor GSM 1800 uplink and downlink spectrum occupancies are represented in Fig. 23, 24, 25 and 26 respectively. The measured results of indoor spectrum occupancy for both uplink and downlink spectrum bands are $43.12 \%$ and $62.13 \%$ respectively. These results conclude that $58.93 \mathrm{MHz}$ spectrum band is unutilized out of the total $\mathrm{MHz}$ spectrum band. Similarly, the measured results of outdoor spectrum occupancy for both uplink and downlink spectrum bands are $59.80 \%$ and $64.45 \%$ respectively. These results conclude that the $47.11 \mathrm{MHz}$ spectrum band is unutilized out of the total $62.2 \mathrm{MHz}$ spectrum band. 


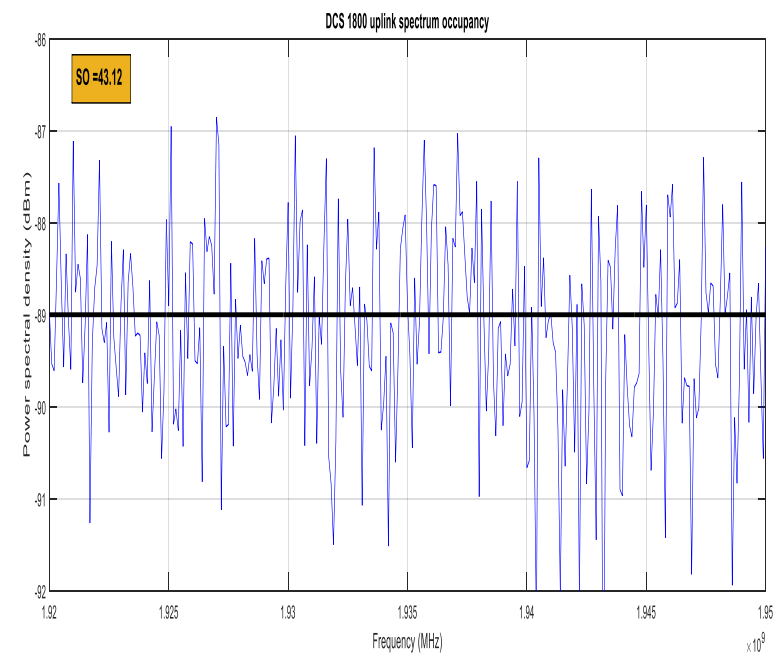

Fig 23. DCS 1800 uplink Spectrum Occupancy.

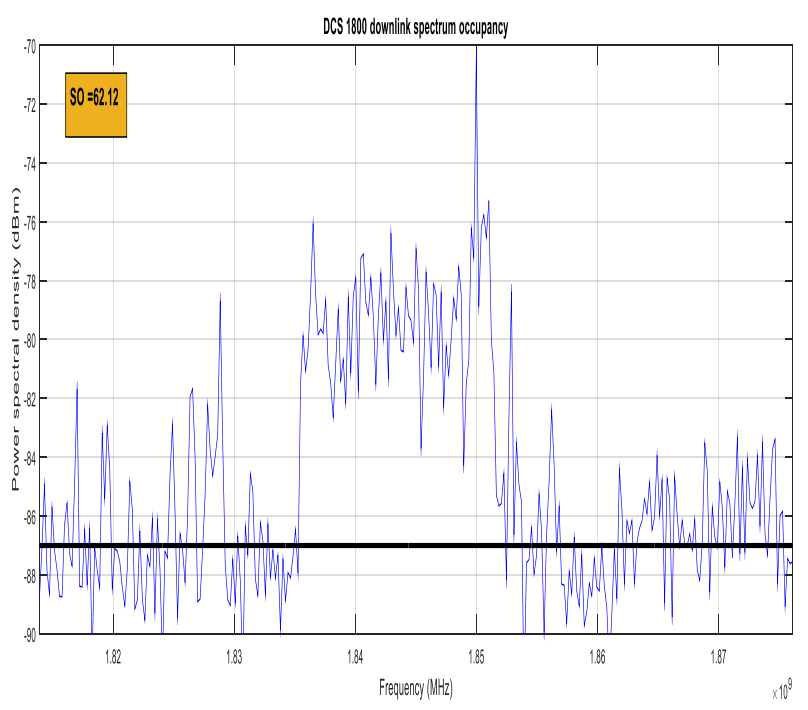

Fig 24. DCS 1800 Downlink Spectrum Occupancy.

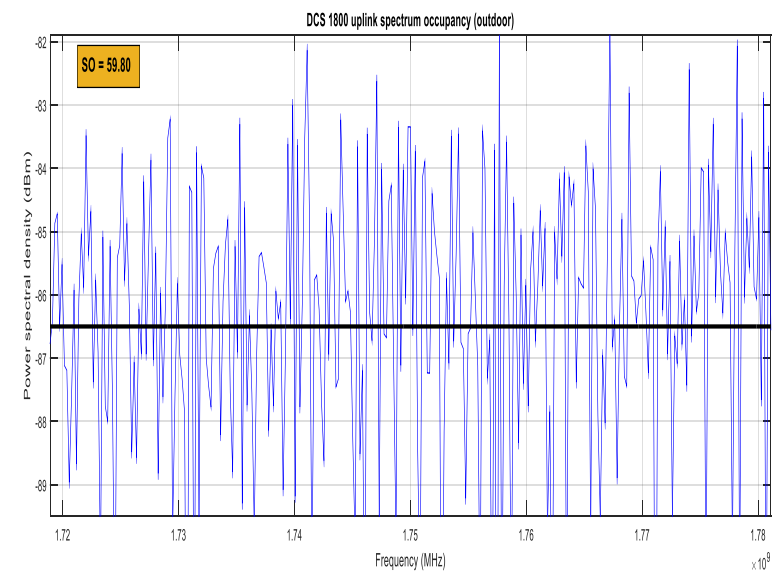

Fig 25. DCS 1800 uplink Spectrum Occupancy (Outdoor).

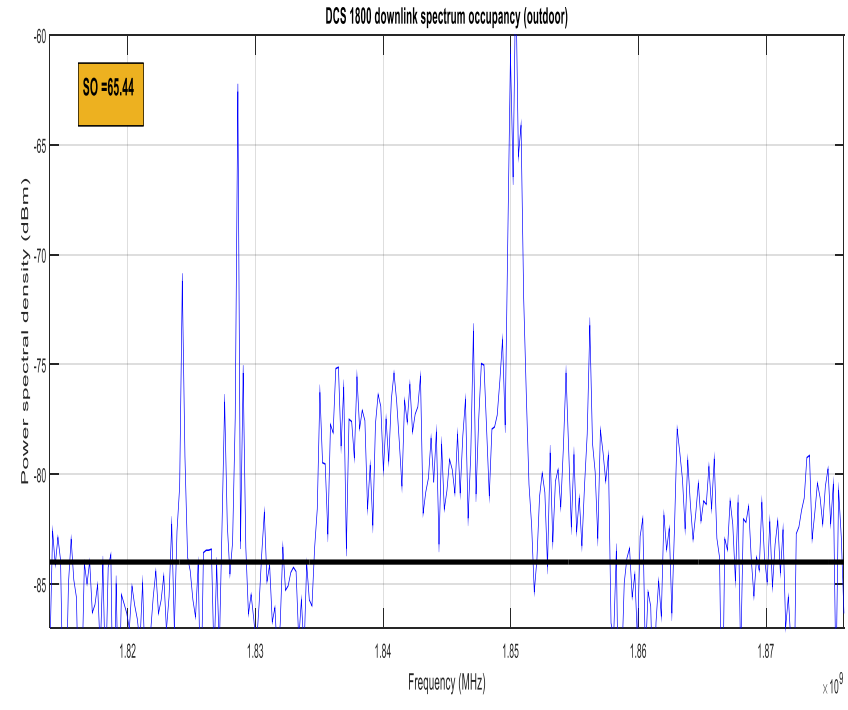

Fig 26. DCS 1800 Downlink Spectrum Occupancy (Outdoor).

\section{G. 2100 Band}

The results of indoor and outdoor 2100 uplink and downlink spectrum occupancies are represented in Fig. 27, 28, 29 and 30, respectively. The measured results of indoor spectrum occupancy for both uplink and downlink spectrum bands are $43.52 \%$ and $77.07 \%$, respectively. These results conclude that the $23.81 \mathrm{MHz}$ spectrum band is unutilized out of the total $30 \mathrm{MHz}$ spectrum band. Similarly, the measured results of outdoor spectrum occupancy for both uplink and downlink spectrum bands are $59.8 \%$ and $86.71 \%$ respectively. These results conclude that the $16.05 \mathrm{MHz}$ spectrum band is unutilized out of the total $30 \mathrm{MHz}$ spectrum band.

Spectrum occupancy and their related unused spectrum of all the GSM cellular operators and GSM 900, 1800 and 2100 bands are illustrated in Table III to Table IX.

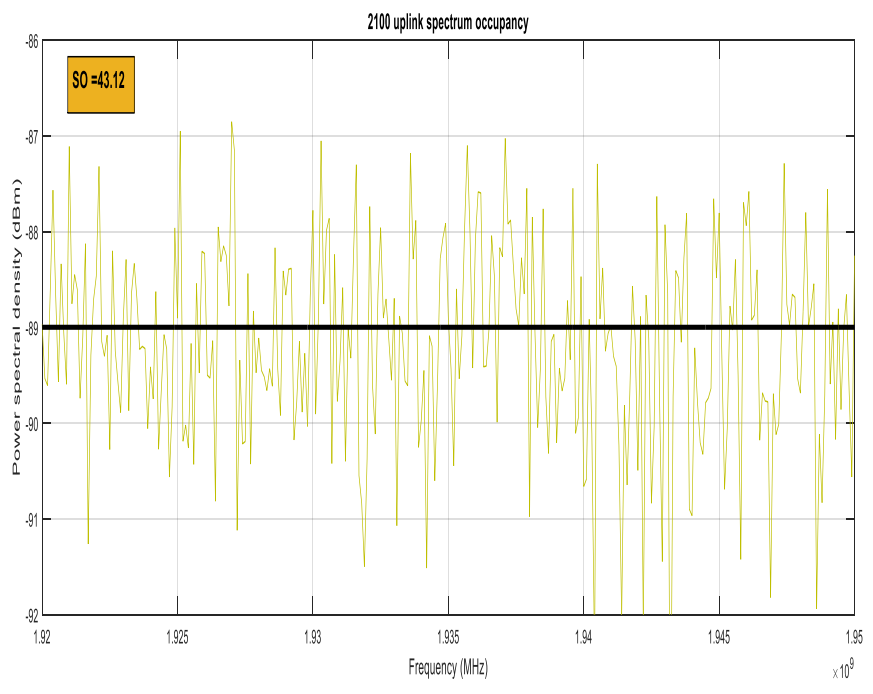

Fig 27. 2100 uplink Spectrum Occupancy. 


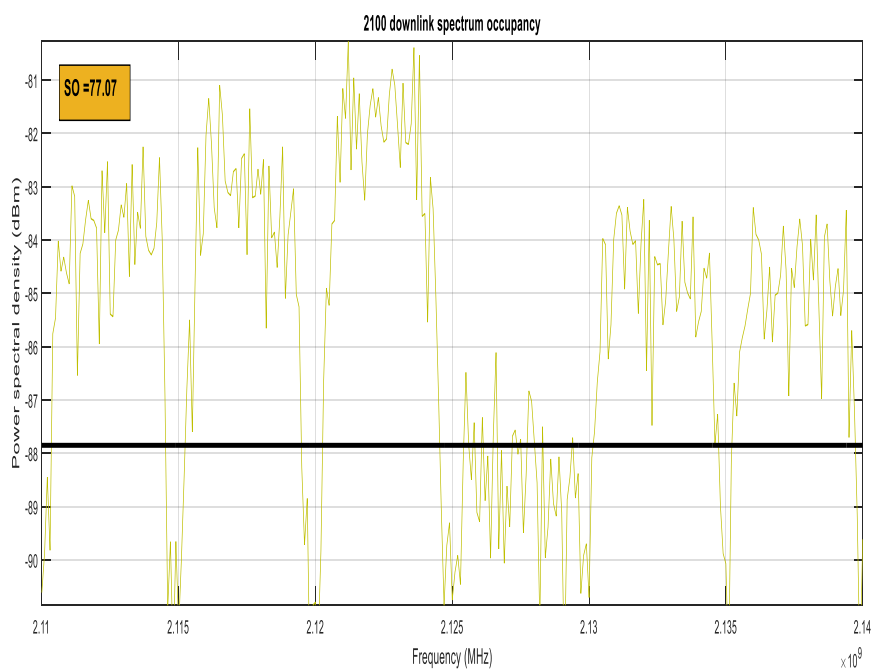

Fig 28. 2100 Downlink Spectrum Occupancy.

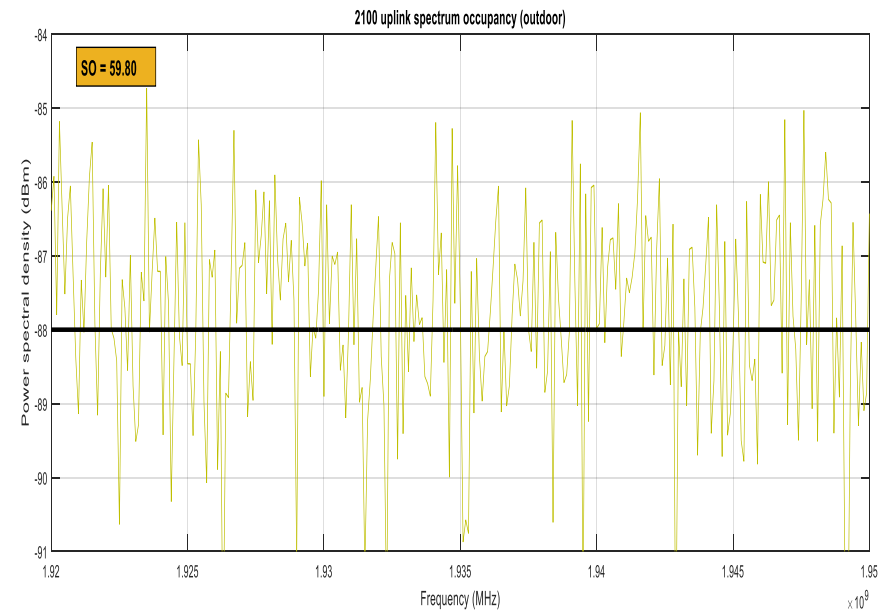

Fig 29. 2100 uplink Spectrum Occupancy (Outdoor).

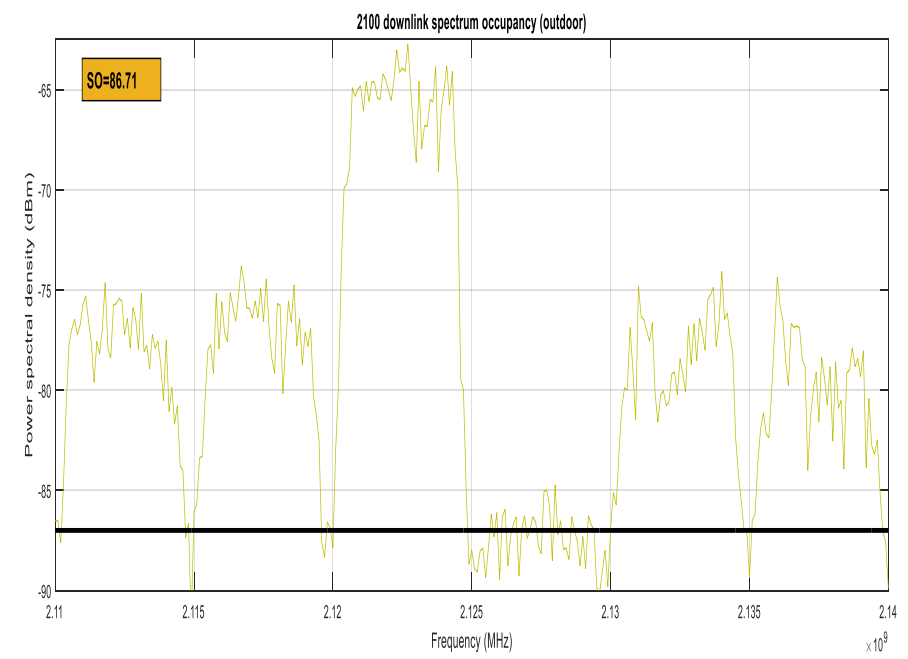

TABLE III. A SUMMARY OF SPECTRUM OCCUPANCY AND UNUSED SPECTRUM (INDOOR: GSM900)

\begin{tabular}{|l|l|l|l|}
\hline \multicolumn{2}{|l|}{ GSM SERVICE PROVIDERS } & $\begin{array}{l}\text { Spectrum } \\
\text { occupancy }(\%)\end{array}$ & $\begin{array}{l}\text { Unused Spectrum } \\
(\mathrm{MHz})\end{array}$ \\
\hline \multirow{2}{*}{$\begin{array}{l}\text { Jazz } \\
\text { (Mobilink) }\end{array}$} & Uplink & 61.794 & 2.90 \\
\cline { 2 - 4 } & Downlink & 61.4618 & 2.92 \\
\hline \multirow{3}{*}{ Ufone } & Uplink & 42.1927 & 4.30 \\
\cline { 2 - 4 } & Downlink & 91.0299 & 0.68 \\
\hline \multirow{3}{*}{ Telenor } & Uplink & 66.113 & 1.63 \\
\cline { 2 - 4 } & Downlink & 60.7973 & 1.88 \\
\hline \multirow{3}{*}{ Jazz (Warid) } & Uplink & 69.7674 & 1.45 \\
\cline { 2 - 4 } & Downlink & 73.0897 & 1.29 \\
\hline \multirow{3}{*}{ Zong } & Uplink & 69.103 & 2.34 \\
\cline { 2 - 4 } & Downlink & 88.0399 & 1.00 \\
\hline \multirow{3}{*}{ GSM 900 } & Uplink & 57.1429 & 10.71 \\
\cline { 2 - 4 } & Downlink & 53.8206 & 11.54 \\
\hline
\end{tabular}

TABLE IV. A SUMMARY OF SPECTRUM OCCUPANCY AND UNUSED SPECTRUM (OUTDOOR: GSM900)

\begin{tabular}{|l|l|l|l|}
\hline \multicolumn{2}{|l|}{ GSM SERVICE PROVIDERS } & $\begin{array}{l}\text { Spectrum } \\
\text { occupancy }(\%)\end{array}$ & $\begin{array}{l}\text { Unused Spectrum } \\
(\mathrm{MHz})\end{array}$ \\
\hline \multirow{3}{*}{ Jazz (Mobilink) } & Uplink & 59.1362 & 3.1 \\
\cline { 2 - 4 } & Downlink & 68.7708 & 2.37 \\
\hline \multirow{3}{*}{ Ufone } & Uplink & 63.1229 & 2.8 \\
\cline { 2 - 4 } & Downlink & 86.711 & 1 \\
\hline \multirow{3}{*}{ Telenor } & Uplink & 56.4784 & 2.08 \\
\cline { 2 - 4 } & Downlink & 66.7774 & 1.59 \\
\hline \multirow{3}{*}{ Zonz (Warid) } & Uplink & 68.4385 & 1.51 \\
\cline { 2 - 4 } & Downlink & 63.1229 & 1.77 \\
\hline \multirow{3}{*}{ GSM 900 } & Uplink & 62.4585 & 2.85 \\
\cline { 2 - 4 } & Downlink & 81.3953 & 1.41 \\
\cline { 2 - 4 } & Uplink & 77.7409 & 5.56 \\
\cline { 2 - 4 } & Downlink & 56.8106 & 10.79 \\
\hline
\end{tabular}

Fig 30. 2100 Downlink Spectrum Occupancy (Outdoor). 
TABLE V. The SA Settings For GSM SERVICE Providers DCS 1800 BAND IN PAKISTAN

\begin{tabular}{|l|l|l|l|l|l|l|l|l|}
\hline \multicolumn{2}{|l|}{ SA PARAMETERS } & $\begin{array}{l}\text { Frequency } \\
\text { range (MHz) }\end{array}$ & $\begin{array}{l}\text { Center frequency } \\
(\mathrm{MHz})\end{array}$ & $\begin{array}{l}\text { Frequency span } \\
(\mathrm{MHz})\end{array}$ & $\begin{array}{l}\text { Resolution } \\
\text { Bandwidth } \\
(\mathrm{KHz})\end{array}$ & $\begin{array}{l}\text { Video } \\
\text { Bandwidth } \\
(\mathrm{KHz})\end{array}$ & $\begin{array}{l}\text { Sweep } \\
\text { time (ms) }\end{array}$ & $\begin{array}{l}\text { Number of frequency } \\
\text { measurement points }\end{array}$ \\
\hline \multirow{2}{*}{ DCS 1800} & Uplink & $1718.9-1781.1$ & 1750 & 62.2 & 200 & 200 & 250 & 301 \\
\cline { 2 - 10 } & Downlink & $1813.9-1876.1$ & 1845 & 62.2 & 200 & 200 & 250 & 301 \\
\hline
\end{tabular}

TABLE VI. DCS 1800 INDOOR AND OUTDOOR

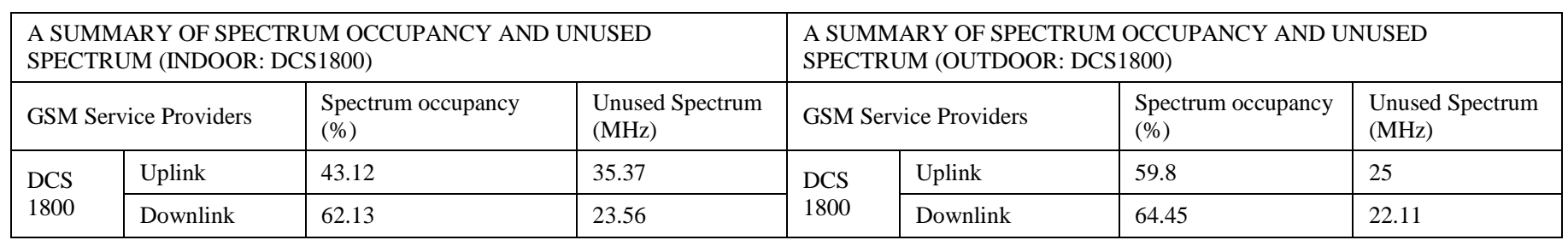

TABLE VII. SPECTRUM ANALYZER SETTINGS 2100 INDOOR AND OUTDOOR

\begin{tabular}{|c|c|c|c|c|c|c|c|c|}
\hline SA parameters & & Frequency range $(\mathrm{MHz})$ & $\begin{array}{l}\text { Center } \\
\text { frequency } \\
(\mathrm{MHz})\end{array}$ & $\begin{array}{l}\text { Frequency } \\
\text { span } \\
(\mathrm{MHz})\end{array}$ & $\begin{array}{l}\text { Resolution } \\
\text { Bandwidth } \\
(\mathrm{KHz})\end{array}$ & $\begin{array}{l}\text { Video } \\
\text { Bandwidth } \\
(\mathrm{KHz})\end{array}$ & $\begin{array}{l}\text { Sweep } \\
\text { time } \\
(\mathrm{ms})\end{array}$ & $\begin{array}{l}\text { Number of } \\
\text { frequency } \\
\text { measurement } \\
\text { points }\end{array}$ \\
\hline \multicolumn{9}{|l|}{$\begin{array}{l}\text { GSM Service } \\
\text { Providers }\end{array}$} \\
\hline \multirow{2}{*}{2100} & Uplink & $1920-1950$ & 1935 & 30 & 200 & 200 & 250 & 301 \\
\hline & Downlink & $2110-2140$ & 2125 & 30 & 200 & 200 & 250 & 301 \\
\hline
\end{tabular}

TABLE VIII. SUMMARY OF 2100 INDOOR AND OUTDOOR

\begin{tabular}{|c|c|c|c|}
\hline \multicolumn{4}{|c|}{$\begin{array}{l}\text { A SUMMARY OF SPECTRUM OCCUPANCY AND UNUSED } \\
\text { SPECTRUM (INDOOR) }\end{array}$} \\
\hline \multicolumn{2}{|c|}{ GSM Service Providers } & $\begin{array}{l}\text { Spectrum } \\
\text { occupancy }(\%)\end{array}$ & $\begin{array}{l}\text { Unused Spectrum } \\
(\mathrm{MHz})\end{array}$ \\
\hline \multirow{2}{*}{2100} & Uplink & 43.52 & 16.94 \\
\hline & Downlink & 77.07 & 6.87 \\
\hline
\end{tabular}

TABLE IX. SUMMARY OF 2100 OUTDOOR

\begin{tabular}{|c|c|c|c|}
\hline \multicolumn{4}{|c|}{$\begin{array}{l}\text { A SUMMARY OF SPECTRUM OCCUPANCY AND UNUSED } \\
\text { SPECTRUM (OUTDOOR) }\end{array}$} \\
\hline \multicolumn{2}{|c|}{ GSM Service Providers } & $\begin{array}{l}\text { Spectrum } \\
\text { occupancy }(\%)\end{array}$ & $\begin{array}{l}\text { Unused Spectrum } \\
(\mathrm{MHz})\end{array}$ \\
\hline \multirow{2}{*}{2100} & Uplink & 59.8 & 12.06 \\
\hline & Downlink & 86.71 & 3.99 \\
\hline
\end{tabular}

\section{H. Smart Network Sharing}

Undoubtedly, the prompt advancement in Telecommunication compels every Mobile operator in Pakistan to be more innovative for the growth of the business. Secondly, cellular customers in Pakistan are increasing at a very fast pace, especially data users. Incumbent operators, Jazz, Telenor, Zong, and Ufone are doing their best efforts to provide not only better services to existing customers but also in a bid to improve their coverage in every corner of the country. Nevertheless, all the mobile service providers are facing the difficult task of significantly increasing the capacity to meet projected demand while keeping CAPEX and OPEX down. In order to achieve the same, infrastructure sharing become a key consideration in operators' planning of the evolution of their networks in the current era. Fig. 31 is showing the number of mobile subscribers in Pakistan until the last quarter (November-2019).

Additionally, to further clarify this, the subscribers of every mobile operator are shown in Fig. 32. These pictures clearly depict the growth in subscribers with each year passing on.

A survey conducted in this project to find out the insights and status of network sharing in Pakistan among operators. Mostly, mobile operators are doing Passive infrastructure sharing due to government regulations. There are four models of Passive infrastructure sharing; model: 1) (Only site space and tower is shared), model: 2) (Site space, tower, and Commercial power is shared), model: 3) (Site Space, tower, Commercial power, and Genset backup is shared), model: 4) (Site Space, tower, commercial power, Genset backup, and DC power is shared). With respect to market share, Jazz is leading in the market and stands number one operator with $37 \%$, while Telenor on second in a row with $28 \%$, whereas Zong is on the third number with $19 \%$ and Ufone is on the fourth position with $15 \%$. With these business opportunities and challenges, mobile operators are witnessing the hardest era in terms of cost. Therefore, to reduce these expenditures, network sharing proved to be the best solution for mobile operators in Pakistan. As per findings, the number of base transceiver stations (BTS) of four operators in Pakistan are shown in below Table X. 


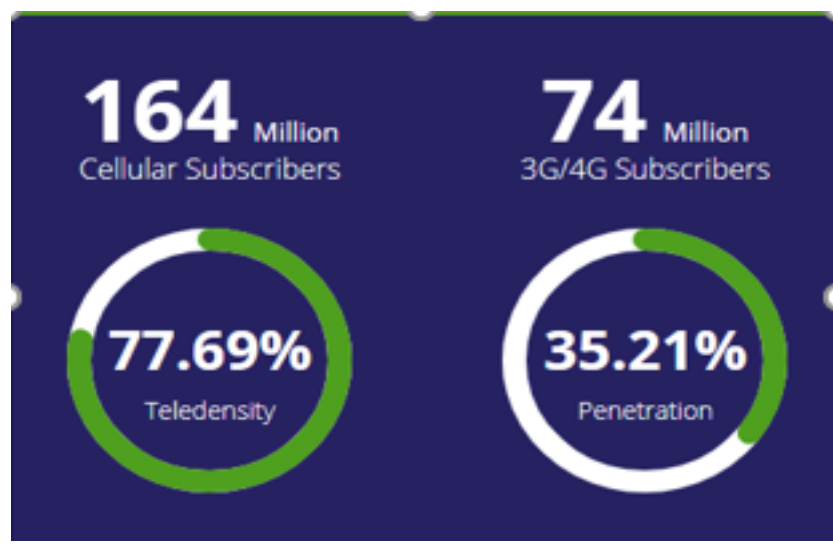

Fig 31. Number of Mobile subscriber in Pakistan.

Annual Cellular Subscribers

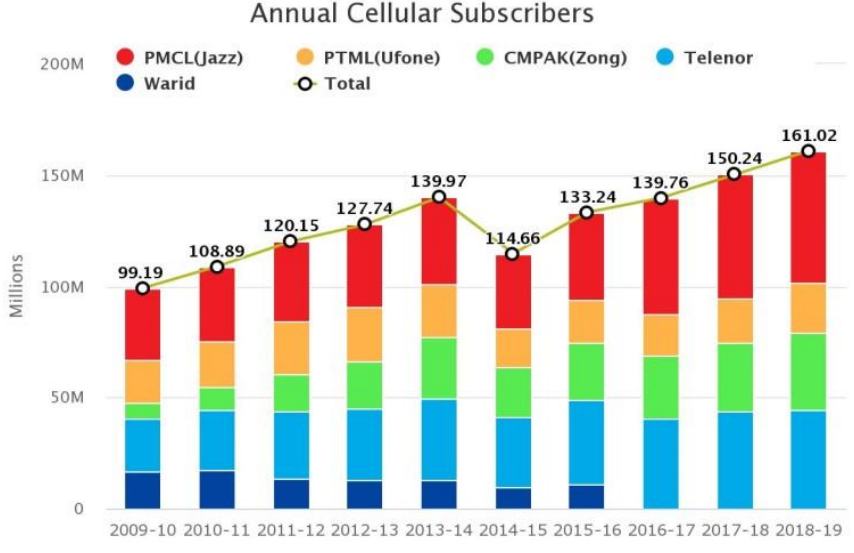

Fig 32. Annual trend of the cellular subscribers in Pakistan.

Interestingly, Telenor is leading among all operators when it comes to network sharing in Pakistan with $37.52 \%$ of Telenor network is shared. While Ufone is on the second number in this competition with $27.69 \%$ of its shared network. Zong is on third with $25.78 \%$ of shared network and Jazz is the last one with $22.63 \%$ network sharing. This clearly shows the incline of all operators towards smart network sharing in the Pakistan Telecom industry as illustrated in Table $\mathrm{X}$ and Fig. 33.

As one of the biggest advantages of the network, sharing is cost-saving, therefore, the details of cost savings provided here. As per this research, operators bear the expenditure of base transceiver station in Pakistan consists of annual rental payment, electricity billing, security expenditure, operation, and maintenance expenditure. Table XI illustrates these details of expenditure.

TABLE X. MONTHLY EXPENDITURE DETAILS IN 2019

\begin{tabular}{|l|l|}
\hline Mobile Operator & Total number of BTS \\
\hline Jazz & 13700 \\
\hline Telenor & 12199 \\
\hline Zong & 12590 \\
\hline Ufone & 9500 \\
\hline
\end{tabular}

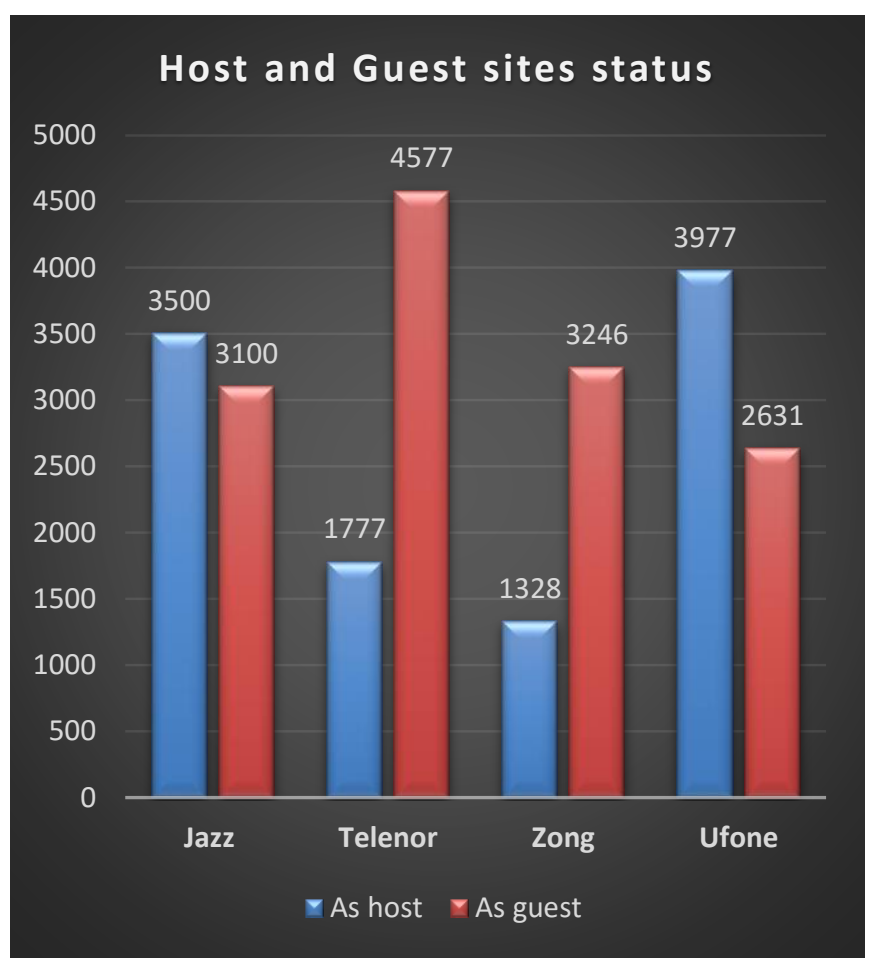

Fig 33. Status of sharing (Host \& Guest) sites of Operators.

TABLE XI. MONTHLY EXPENDITURE DETAILS IN 2019

\begin{tabular}{|l|l|l|}
\hline Monthly expenditure details in 2019 & $\begin{array}{l}\text { Without sharing/Independent site } \\
\text { Expenditure details }\end{array}$ & $\begin{array}{l}\text { With } \\
\text { Sharing/co- } \\
\text { location }\end{array}$ \\
\hline Average Rent & 20 to 50 thousand per month & 0 \\
\hline $\begin{array}{l}\text { Electricity } \\
\text { Expenditure }\end{array}$ & 70 to 80 thousand per month & 0 \\
\hline $\begin{array}{l}\text { Security } \\
\text { Expenditure }\end{array}$ & 12000 & 0 \\
\hline $\begin{array}{l}\text { O\&M of CP \& DG } \\
\text { expenditure }\end{array}$ & 7,000 & 0 \\
\hline Total & 109000 to 149000 & 0 \\
\hline
\end{tabular}

\section{CONCLUSION}

In this paper, we have carried out the spectrum occupancy measurements through SA and plot them in the MATLAB against frequency vs power spectral density. We have measured the spectrum occupancies of three bands i.e. 900, 1800 and 2100 bands for both indoor as well as outdoor spectrum bands and found out that the majority of the spectrum band is unutilized. The results of measured spectrum occupancies are illustrated in Table III to Table IX. In addition, it is noted that the overall bandwidth utilization ratio of all the cellular service providers is not $100 \%$, which can be utilized with the help of CR. Thus, CR can be the optimal solution to improve the spectrum utilization ratio of all the three bands of uplink and downlink spectrum bands in Pakistan. Moreover, the Network sharing became the norm for Telecom industry to control cost and expenditure. 


\section{FUTURE WORK}

This research work can give a promising result to open the doors of a new era of wireless communication in Pakistan in terms of network sharing. Spectrum bands will become technological free/neutral as per the demand of this day and spectrum occupancy will play a vital role for it. Furthermore, it is likely that $3 \mathrm{G}$ infrastructure may vanish in future, as the $3 \mathrm{G}$ architecture entails extensive hardware replacing when shifting from $2 \mathrm{G}$ to $3 \mathrm{G}$ (expensive). $4 \mathrm{G} / \mathrm{LTE}$ is an all IP network and do not need conventional hardware though it only requires switches and servers. It is therefore likely that a third party vendor/contractor may provide site allocation and infrastructure to cellular operators, reducing OPEX and CAPEX by the concept of smart network sharing.

\section{REFERENCES}

[1] H. Li, X. Ding, Y. Yang, Z. Xie, and G. Zhang, "Online Spectrum Prediction with Adaptive Threshold Quantization," IEEE Access, vol. 7, pp. 174325-174334, 2019, DOI: 10.1109/ACCESS.2019.2957335.

[2] H. Qi, S. Member, X. Zhang, and S. Member, "Low-Complexity Subspace-Aided Compressive," IEEE Trans. Veh. Technol., vol. 68, no. 12, pp. 11762-11777, 2019, DOI: 10.1109/TVT.2019.2937649.

[3] Y. Luo, J. Dang, and Z. Song, "Optimal Compressive Spectrum Sensing Based on Sparsity Order Estimation in Wideband Cognitive Radios," IEEE Trans. Veh. Technol., vol. 68, no. 12, pp. 12094-12106, 2019, DOI: 10.1109/TVT.2019.2948966.

[4] Y.-H. Liu, S. Sheelavant, M. Mercuri, P. Mateman, and M. Babaie, "An Ultralow Power Burst-Chirp UWB Radar Transceiver for Indoor Vital Signs and Occupancy Sensing in 40-nm CMOS," IEEE Solid-State Circuits Lett., vol. 2, no. 11, pp. 256-259, 2019, DOI: 10.1109/lssc.2019.2951423.

[5] S. Ali, Z. Chen, and F. Yin, "Spectrum Occupancy of Cellular Networks in Pakistan for Cognitive Radio - Measurements using Spectrum Analyzer," Int. J. Inf. Electron. Eng., vol. 6, no. 1, pp. 26-31, 2015, DOI: 10.18178/ijiee.2016.6.1.588.

[6] D. Capriglione, G. Cerro, L. Ferrigno, and G. Miele, "Effects of Real Instrument on Performance of an Energy Detection-Based Spectrum Sensing Method," vol. 68, no. 5, pp. 1302-1312, 2019.

[7] M. Ozturk, M. Akram, S. Hussain, and M. A. Imran, "Novel QoS-Aware Proactive Spectrum Access Techniques for Cognitive Radio Using Machine Learning," IEEE Access, vol. 7, pp. 70811-70827, 2019, DOI: 10.1109/ACCESS.2019.2918380.
[8] N. A. El-Alfi, H. M. Abdel-Atty, and M. A. Mohamed, "Sub-Nyquist Cyclostationary Detection of GFDM for Wideband Spectrum Sensing," IEEE Access, vol. 7, pp. 86403-86411, 2019, DOI: 10.1109/ACCESS.2019.2925047.

[9] D. V. Kalkitware, "Wireless Body area networks for patient monitoring," Eng. Technol., vol. 2, no. 6, pp. 215-222, 2016, DOI: 10.1049/iet-com.

[10] M. V. Lipski and R. M. Narayanan, "Applying Periodic Retraining to Survival Analysis-Based Dynamic Spectrum Access Algorithms," Proc. - IEEE Mil. Commun. Conf. MILCOM, vol. 2019-October, pp. 871876, 2019, DOI: 10.1109/MILCOM.2018.8599767.

[11] G. Cerro and G. Miele, "A stand-alone sensor for spectrum occupancy monitoring in dynamic spectrum access framework," SAS 2019 - 2019 IEEE Sensors Appl. Symp. Conf. Proc., pp. 1-6, 2019, DOI: 10.1109/SAS.2019.8706108.

[12] L. N. Man, S. Committee, and I. Computer, Part 22 : Cognitive Wireless RAN Medium Access Control ( MAC ) and Physical Layer ( PHY ) Specifications: Policies and Procedures for Operation in the TV Bands IEEE Computer Society, vol. 2015, no. July. 2011.

[13] A. Bousia, E. Kartsakli, A. Antonopoulos, L. Alonso, and C. Verikoukis, "Sharing the small cells for energy-efficient networking: How much does it cost?," 2014 IEEE Glob. Commun. Conf. GLOBECOM 2014, pp. 2649-2654, 2014, DOI: 10.1109/GLOCOM.2014.7037207.

[14] T. International et al., "Mobile Cellular Network Infrastructure Sharing Models Among Gsm," vol. 3, no. 4, pp. 12-13, 2015.

[15] L. Anchora et al., "Resource allocation and management in multioperator cellular networks with shared physical resources," Proc. Int. Symp. Wirel. Commun. Syst., pp. 296-300, 2012, DOI: 10.1109/ISWCS.2012.6328377.

[16] L. Chihana and D. Banda, "Telecommunication Tower Sharing Effects on Network Providers in Zambia," vol. 7, no. 4, pp. 89-93, 2017, DOI: 10.5923/j.scit.20170704.01.

[17] "Breaking: Telenor Wins 4G Spectrum in Pakistan," 2016. [Online]. Available: https://propakistani.pk/2016/06/09/breaking-telenor-wins-4gspectrum-in-pakistan/. [Accessed: 10-Feb-2020].

[18] "Mobilink, Warid become Jazz after the merger," 2017. [Online]. Available: https://www.dawn.com/news/1313181. [Accessed: 17-Feb2020].

[19] "Ufone is Going 4G/LTE in Pakistan," 2019. [Online]. Available: https://propakistani.pk/2019/02/09/ufone-is-going-4g-lte-in-pakistan/. [Accessed: 17-Feb-2020].

[20] "Pakistan grants Jazz, Zong 5G trial licenses," 2020. [Online]. Available: https://www.mobileworldlive.com/asia/asia-news/pakistangrants-jazz-zong-5g-trial-licences/. [Accessed: 17-Feb-2020]. 